\title{
SAÚDE OCUPACIONAL: CONSIDERAÇÕES A RESPEITO DA PERDA AUDITIVA INDUZIDA POR RUÍDO E DA DISFONIA
}

\author{
Laura Corrêa de Barros \\ Instituto de Ciências Gerenciais - Pontifícia Universidade Católica de Minas Gerais \\ lauracbarros@yahoo.com.br \\ João Evangelista de Almeida Saint' Yves \\ Instituto de Ciências Gerenciais - Pontifícia Universidade Católica de Minas Gerais \\ jeasyves@pucminas.br
}

This study provides some information about occupational health, more specifically about noise-induced hearing loss and voice disorders caused by the attempt to overcome background noise. Repeated exposures to excessive sound levels can lead to noise-induced hearing loss and voice disorders. Several studies have been conducted in order to suggest best means to control noise. Among the professionals involved in the hearing loss prevention are the industrial engineers and operations managers. This study also suggests that many of the workers that perform their job in a noisy place have to raise their voices to be heard over the sound environment, which could cause voice disorders. Therefore, some considerations have been made about the aspects of noise control projects and ways to prevent hearing loss and voice disorders in a noisy environment.

Key words: excessive sound levels, hearing loss, voice disorders.

\section{Introdução}

O ruído nas empresas é apontado por diversos autores como a principal causa da PAIR (Perda Auditiva Induzida por Ruído), além de poder causar outros transtornos, como a Disfonia por esforço decorrente da competição com o ruído de fundo. A PAIR é reconhecida pela Legislação Brasileira como doença ocupacional, ao contrário da Disfonia, que ainda enfrenta discussões que restringem a possibilidade de indenização somente aos considerados "profissionais da voz". Entretanto, a importância sobre toda e qualquer forma de prejuízo à saúde do trabalhador deve compor a gama de preocupações das entidades externas e internas responsáveis por garantir boas condições do ambiente de trabalho.

O Engenheiro de Produção, além de conhecer as bases técnicas de realização do trabalho, deve possuir habilidades de gestão. Este profissional também faz parte da equipe destinada ao estudo das condições de trabalho da empresa. A Ergonomia e a Segurança do Trabalho são aspectos muito destacados atualmente, e profissionais de diferentes áreas realizam pesquisas buscando por melhorias e adaptações que otimizem as forças humanas, assunto considerado delicado pela literatura sobre as ciências gerenciais.

Assim, o objetivo do presente trabalho consiste em apresentar conhecimentos básicos sobre a PAIR e a Disfonia, demonstrar base legal sobre estas doenças e relatar um estudo de caso. Este tema é justificado pela crescente preocupação com a saúde do trabalhador e as indenizações pagas pelas empresas legalmente processadas. Portanto, é de interesse do Engenheiro de Produção, bem como de todos os especialistas envolvidos nos 
estudos ergonômicos, obter informações sobre estas e outras doenças para, então, criar tecnologias de prevenção e controle.

\section{A Perda Auditiva Induzida por Ruído}

O audiologista industrial é o profissional que fornece serviços de consultoria sobre a preservação da audição a empresas cujos operários são expostos a níveis elevados de ruído (BESS \& HUMES, 1998, p. 19). A surdez ocupacional é definida como a perda auditiva que decorre da exposição prolongada a ruído contínuo e intenso, podendo afetar os indivíduos que vivem ou trabalham em ambientes onde os níveis de intensidade do ruído é superior a 85dbNPS (RUSSO \& SANTOS, 1993, p. 246). A surdez ocupacional é também chamada de PAIR (Perda Auditiva Induzida por Ruído), de Disacusia Induzida pelo Ruído, de Surdez Profissional e de Perda Auditiva Neurossensorial por Exposição Continuada a Níveis Elevados de Pressão Sonora de Origem Ocupacional.

Os indivíduos afetados pela PAIR podem relatar zumbido persistente de longa duração e dificuldade para ouvir determinados sons, em geral, sons agudos, como, por exemplo, campainha de telefone, tic-tac do relógio, etc. Os principais achados audiológicos são perda auditiva neurossensorial bilateral com quedas mais significativas nas freqüências de 3000, 4000 e $6000 \mathrm{~Hz}$, limiar tonal normal para $8000 \mathrm{~Hz}$, SRT (Speech Reception Threshold ou Limiar de Recepção da Fala) próximo da média das freqüências da fala e IRF (Índice de reconhecimento da fala) pouco afetado inicialmente, mas que poderá ser alterado com a evolução do processo (RUSSO \& SANTOS, 1993, p. 248). Segundo BESS \& HUMES (1998, p. 188), influem na perda auditiva induzida por ruído a duração da exposição, a susceptibilidade do indivíduo e as características acústicas do som, como sua intensidade, duração e conteúdo de freqüência (espectro de amplitude).

A medida do som é realizada através de dois principais modos: pela freqüência, expressa em Hertz (Hz) e pela intensidade, expressa em decibéis (dB). A escala dB NPS ou SPL (Sound Pressure Level) expressa as medidas em nível de pressão sonora. A expressão dB (A), segundo o anexo B da Resolução no 252 de 01 de Fevereiro de 1999 do Conselho Nacional do Meio Ambiente - CONAMA, é definida como "unidade do nível de pressão sonora em decibel, ponderada pela curva de resposta (A) para quantificação de nível de ruído”. A escala dB NA ou HL (Hearing Level) significa nível auditivo, ou seja, a sensação de intensidade (BESS \& HUMES, 1998). Com base nessas unidades de medida, a portaria Brasileira do Ministério do Trabalho n. 3.214/78 fixa o nível de ruído máximo permitido em relação à jornada de trabalho, válido para ambientes industriais onde existe ruído de máquinas e processos ruidosos:

\begin{tabular}{|l|l|}
\hline NPS dB (A) & $\begin{array}{l}\text { Máxima exposição diária } \\
\text { permissível }\end{array}$ \\
\hline 85 & 08 horas \\
86 & 07 horas \\
87 & 06 horas \\
88 & 05 horas \\
89 & 04 horas e 30 minutos \\
90 & 04 horas \\
91 & 03 horas e 30 minutos \\
92 & 03 horas \\
93 & 02 horas e 30 minutos \\
94 & 02 horas e 15 minutos \\
95 & 02 horas \\
96 & 1 hora e 45 minutos \\
\hline
\end{tabular}




\begin{tabular}{|l|l|}
\hline 98 & 1 hora e 15 minutos \\
100 & 01 horas \\
102 & 45 minutos \\
104 & 35 minutos \\
105 & 30 minutos \\
106 & 25 minutos \\
108 & 20 minutos \\
110 & 15 minutos \\
112 & 10 minutos \\
114 & 08 minutos \\
115 & 07 minutos \\
\hline
\end{tabular}

Quadro 1: Limites de NPS. Fonte: Portaria 3214/1978

Toda organização deve possuir órgãos internos encarregados de garantir boas condições do ambiente de trabalho. Dentro de cada empresa existe uma Comissão Interna de Prevenção de Acidentes - CIPA -, regida pela Lei $n^{\circ} 6.514$ de 22/12/77 e regulamentada pela NR-5 do Ministério do Trabalho, aprovada pela portaria $n^{0} 3.214$ de 08/06/76, publicada no D.O.U. de 29/12/94 e modificada em 15/02/95. Analogamente a esta lei, de acordo com a NR-9 da Portaria $\mathrm{n}^{\mathrm{o}} 3.214$ do Ministério do Trabalho, toda empresa deve ter um Programa de Prevenção de Riscos Ambientais - PPRA.

Visando garantir a integridade auditiva do trabalhador, foi criado o PCA (Programa de Conservação Auditiva), com base nos aspectos colocados pela OSHA (Occupational Safety and Health Administration). No Brasil, uma portaria do INSS (Diário Oficial n ${ }^{\circ}$ 131, 11/07/1997, seção 3 págs. 14244 à 14249, edital $n^{\circ} 3$ de 09/07/1997, anexo II) faz considerações à respeito da Perda Auditiva por Ruído Ocupacional e sobre o PCA. Esta lei coloca que a organização deste programa é de responsabilidade da empresa e envolve a formação de uma equipe multidisciplinar composta por "profissionais da área de saúde e segurança, da gerência industrial e de recursos humanos da empresa e, principalmente, dos trabalhadores".

Segundo as diretrizes estabelecidas por esta portaria, um PCA deve conter, basicamente, as seguintes etapas, com destaque para a etapa 2, pois é de interesse dos engenheiros de produção:

1) Monitoramento da exposição a nível de pressão sonora elevado;

2) Controles de engenharia e administrativos: são os elementos mais importantes de um PCA, pois somente por meio da redução do nível de pressão sonora elevado ou da exposição é que se consegue prevenir os danos ocasionados pelo nível de pressão sonora elevado. As medidas de engenharia são definidas como toda modificação ou substituição de equipamentos que cause alteração física na origem ou na transmissão do nível de pressão sonora elevado (com exceção dos EPIs - Equipamentos de Proteção Individual), reduzindo os níveis sonoros que chegam no ouvido ao trabalhador. São exemplos de medidas de engenharia a instalação de silenciadores, enclausuramento de máquinas, redução de vibração das estruturas, revestimento de paredes com materiais de absorção sonora, etc. As medidas administrativas são aquelas que têm por objetivo alterar o esquema de trabalho ou das operações, produzindo redução da exposição, como por exemplo, rodízio de empregados nas áreas de nível de pressão sonora elevado, funcionamento de determinadas máquinas em turnos ou horários com menor número de pessoas presentes, etc.

3) Monitoramento audiométrico;

4) Indicação de Equipamentos de Proteção Individual - EPI;

5) Educação e motivação;

6) Conservação de registros; 
7) Avaliação da eficácia e eficiência do programa.

\section{A Disfonia}

O fonoaudiólogo e o otorrinolaringologista são os dois profissionais mais envolvidos no processo de avaliação dos distúrbios vocais. O otorrinolaringologista se encarrega dos exames invasivos, como a laringoscopia (LOPES FILHO \& CAMPOS, 1994), enquanto o fonoaudiólogo realiza a avaliação perceptiva da voz. Combinando os dados, estes profissionais realizam o diagnóstico patológico e estabelecem uma abordagem terapêutica adequada.

A disfonia é definida por BEHLAU \& PONTES (1995, p. 19) como "um distúrbio de comunicação, no qual a voz não consegue cumprir seu papel básico de transmissão da mensagem verbal e emocional de um indivíduo". A disfonia pode se manifestar através de vários sinais, tais como esforço à emissão, dificuldade de manter a voz, cansaço ao falar, rouquidão, falta de volume e projeção, etc. (BEHLAU \& PONTES, 1995 p. 19). Algumas noções sobre a produção vocal, tais como inspirar antes de falar, articular corretamente e com a boca aberta, não competir com ruído de fundo e usar roupas confortáveis, principalmente na região do pescoço e do tórax, são conhecimentos muito simples para evitar alterações de voz (BEHLAU, RODRIGUES, AZEVEDO, GONÇALVES, \& PONTES, In: LOPES FILHO, Otacílio. 1997, p. 609).

Alguns indivíduos são considerados profissionais da voz por depender da utilização desta para realizar seu trabalho, como os professores, cantores, atores, locutores e operadores de telemarketing. A disfonia, mesmo quando ocorre nestes indivíduos, ainda não é considerada, legalmente, uma doença ocupacional, embora esta seja uma questão polêmica entre os especialistas da área. A lei, no entanto, já aprova o programa de conservação da voz para professores, que geralmente apresentam maiores problemas relacionados ao mau uso da voz e possuem menos informações e preparação para o desempenho vocal adequado.

É possível observar que outros profissionais, tais como os gerentes, também dependem da voz para realizar o trabalho de orientar os devidos subordinados. Estes, por sua vez, dependem da voz para trocar informações no próprio ambiente de trabalho. Se estes indivíduos fazem grande esforço para que a intensidade da voz supere os níveis de ruído de fundo, a disfonia pode se instalar e prejudicar o trabalho a ser realizado.

A disfonia também pode ser um sintoma secundário a outras condições, tais como alergias e exposição à poluição e agentes químicos, como ocorre freqüentemente em certos ambientes de trabalho. $\mathrm{O}$ aumento da intensidade da voz decorrente do ruído ambiental é uma das principais causas da disfonia por esforço. Durante a realização deste trabalho não foi possível encontrar literatura que relatasse casos estabelecendo considerações a respeito da disfonia instalada em trabalhadores devido ao esforço vocal decorrente do ruído no setor operacional de uma empresa, apesar de vários estudos apontarem a dificuldade de compreender a conversa em ambientes ruidosos.

Segundo GRANDJEAN (1998, p. 269), a sensibilidade do ouvido para a conversa com um colega diminui com o crescente nível de ruído. Em uma sala de trabalho, a compreensão da conversa é amplamente determinada pelo nível de ruído da sala e pela intensidade sonora da voz (GRANDJEAN, 1998, p.270). A pressão sonora da voz humana em uma sala oscila em intensidade normal de voz a $1 \mathrm{~m}$ de distância nos seguintes valores (GRANDJEAN, 1998, p. 271):

\begin{tabular}{|l|l|}
\hline Conversa normal tranqüila & $60-65 \mathrm{~dB}$ \\
\hline Ditado & $65-70 \mathrm{~dB}$ \\
\hline Relator de uma conferência & $65-75 \mathrm{~dB}$ \\
\hline
\end{tabular}




\begin{tabular}{|l|l|}
\hline Preleção em um auditório & $70-80 \mathrm{~dB}$ \\
\hline Chamado alto & $80-85 \mathrm{~dB}$ \\
\hline
\end{tabular}

Quadro 2: Pressão sonora da voz humana. Fonte: GRANDJEAN, 1998, p.271.

Ainda segundo GRANDJEAN (1998, p. 271), “(...) quando se usa a voz em um trabalho profissional, freqüentemente para finalidades de informações ou ditados, ela não deveria ultrapassar 65 a $70 \mathrm{~dB}$ (a $1 \mathrm{~m}$ de distância). Para que esta voz seja entendida sem perturbações e sem esforço, o nível geral, conforme já explicado, não deve ser maior que 55 a 60 dB".

A avaliação perceptiva da voz, realizada pelo fonoaudiólogo, tem caráter subjetivo, apresentando dificuldades na padronização dos termos empregados. Segundo BEHLAU, RODRIGUES, AZEVEDO, GONÇALVES, \& PONTES (In: LOPES FILHO, Otacílio, 1997, p. 620), visando universalizar a avaliação da qualidade vocal, o Comitê para testes da função fonatória da JAPAN SOCIETY OF LOGOPEDICS AND PHONIATRICS propôs a Escala GRBAS, composta de cinco tipos de alterações na qualidade vocal, cada uma com quatro níveis de anormalidade da voz - discreto, moderado, severo e extremo. A sigla GRBAS corresponde aos cinco tipos de alteração vocal. São eles: G (grade), representando o grau geral da disfonia do paciente; R (rough) para rouquidão; B (breathy) para a soprosidade; A (astheny) para a astenia vocal e S (strain) para a tensão fonatória. Cada um desses principais parâmetros é avaliado numa escala de quatro pontos, como ausente, discreto, moderado e severo. Apesar de várias limitações, a escala japonesa representa uma importante tentativa de padronização da avaliação perceptiva e modificações têm sido realizadas para melhorá-la.

\section{Estudo de Caso}

A MCR do Brasil Ltda. é uma empresa de metalurgia que tem como atividades operacionais básicas o corte e a solda de chapas metálicas, caracterizando a prestação de serviços de fabricação e usinagem pesada visando a constituição de outros equipamentos. Seu parque industrial está localizado em Contagem, região metropolitana de Belo Horizonte, Minas Gerais, e inclui um galpão industrial em estrutura metálica, com pé direito de 8 metros, lanternin e área coberta de $4.500 \mathrm{~m}^{2}$. Dentro deste galpão encontram-se diversos equipamentos, dentre eles calandras, compressores, elevadores hidráulicos, furadeiras, guindastes, mandriladoras, máquinas de pintura, pontes rolantes, dobradeira de tubos, prensas, rosqueadeira, serra e demais equipamentos de corte e solda em geral (Relatório de Bens da MCR do Brasil Ltda., 2002).

O funcionamento das máquinas depende diretamente da demanda a ser atendida. Portanto, o ruído provocado pode ser menor ou maior, variando de acordo com o número e o tipo de máquinas em operação. A partir de uma breve análise dos histogramas de medição de ruído realizado pela empresa de consultoria Ajax Segurança e Medicina do Trabalho Ltda. (Maio/2001), é possível concluir que a grande maioria dos funcionários está exposta a níveis de ruído que exigem a utilização de equipamentos de proteção e demais medidas de controle de ruído.

Por exemplo, durante o período em que foi realizada a medição do ruído, foram registrados níveis médios de $104.5 \mathrm{~dB}(\mathrm{~A})$ para o ajudante de caldeiraria às 13:50h, e de $100.7 \mathrm{~dB}(\mathrm{~A})$ para o bombeiro hidráulico às 15:30h. (Histogramas segundo Ájax Segurança e Medicina do Trabalho Ltda., Maio/2001). Estes níveis justificam a necessidade de implantação de um PCA objetivando a prevenção da surdez ocupacional, uma vez que a jornada padrão de trabalho é de $8 \mathrm{~h}$ por dia e o ruído supera os $85 \mathrm{~dB}$ previstos por lei (Tabela 1). Os trabalhadores da MCR do Brasil já utilizam os protetores auriculares e 
realizam audiometrias periódicas, sendo que nenhum caso de perda auditiva foi identificado até o momento.

Para investigar possíveis transtornos vocais, foram realizadas visitas ao galpão para observar a dinâmica da comunicação, uma avaliação do tipo triagem e uma entrevista. As observações visaram identificar a forma como os trabalhadores conversam uns com os outros diante do problema do ruído e da utilização dos protetores auditivos. A avaliação do tipo triagem consistiu em contagem dos números de 1 a 20 por cada trabalhador, sendo os dados registrados segundo a percepção do avaliador de acordo com os seguintes aspectos: voz normal ou alterada, caracterização da alteração (rouquidão, aumento de intensidade, tensão na região do pescoço, falta de coordenação entre respiração e fala, articulação ou outra) e grau da alteração (discreto, moderado e grave). Para aqueles que apresentaram alteração, foi perguntado a época de surgimento do problema de voz em relação à época em que iniciou o trabalho em ambiente ruidoso, além de presença de tabagismo, cansaço ao falar, pigarro freqüente ou outro sintoma. A entrevista consistiu em perguntas gerais, como a questão acerca da necessidade de aumento da intensidade da voz para estabelecer a comunicação entre os trabalhadores.

Com base nas visitas ao galpão foi possível observar que os trabalhadores, quando necessário, emitem mensagens verbais a uma distância igual ou inferior a $1 \mathrm{~m}$, considerando a distância estabelecida entre a cavidade oral do locutor e o pavilhão auricular do receptor. Se a distância é maior, o supervisor e os trabalhadores utilizam gestos para chamar o outro para perto, pois o próprio nível de ruído e a distância fazem com que se torne inútil a tentativa de comunicação verbal direta. A utilização dos protetores auditivos também acarreta em aumento adicional na intensidade vocal.

Foram submetidos à triagem e à entrevista 14 indivíduos que operam máquinas diferentes. Dos trabalhadores entrevistados, 14 (100\%) relataram que aumentam a intensidade de voz ao emitir a mensagem e que esta deve ser repetida pelo menos uma vez para garantir a compreensão íntegra por parte do receptor. Destes 14, 4 (28,5\%) relataram que se acostumaram a falar alto, mesmo fora do ambiente de trabalho. Apesar de nenhum trabalhador apresentar uma queixa vocal específica ou outro sintoma, $6(42,8 \%)$ relataram desconforto ao aumentar a intensidade de voz, 2 (14,2\%) notam deterioração da voz ao final do expediente e 7 (50\%) mencionaram o hábito de pigarrear, sendo que dentre estes, 4 (57\%) fumam entre $1 / 2$ e 2 maços/dia. Com base na triagem, foram identificados $6(42,8 \%)$ trabalhadores que, segundo a percepção do avaliador, apresentaram rouquidão discreta, e 1 (7\%) com intensidade de voz aumentada, sendo que os demais apresentaram intensidade normal ou ligeiramente baixa. Destes 6 que apresentaram rouquidão discreta, nenhum relatou que a voz se modificou após a contratação para trabalhar em ambiente ruidoso e dentre eles $2(33,3 \%)$ fumam entre $1 / 2$ e 2 maços/dia. A articulação apresentou-se normal na maioria dos indivíduos, com pequenas variações que não afetam a comunicação em si.

A partir destes dados é possível levantar a hipótese de que, a longo prazo, o aumento da intensidade de voz, resultante da competição com o ruído de fundo e objetivando superar a filtragem dos sons realizada pelos protetores auditivos, pode levar à disfonia. Outros fatores como o tabagismo e o hábito adquirido de pigarrear e de falar alto em tempo integral podem atuar concomitamente com o aumento de intensidade da voz favorecendo o aparecimento de alterações vocais. Como sugestões para prevenir a instalação destas alterações nos trabalhadores é possível citar a orientação aos trabalhadores quanto à utilização da voz e aos sintomas da disfonia por esforço decorrente da competição com o ruído de fundo, a padronização e a utilização ampla de gestos, a leitura labial (observar os lábios do interlocutor e a articulação das palavras visando deduzir o significado da mensagem transmitida) e a utilização de outros dispositivos de amplificação da voz (como microfones), entre outras. 


\section{Considerações Finais}

Muitos programas têm sido implementados para controlar os níveis de ruído dentro da organização. Estes programas são submetidos a avaliações constantes e sofrem adaptações para melhor atender às necessidades da empresa e do trabalhador. Também foi possível constatar que a lei constitui um instrumento para regulamentar as obrigações da organização e os direitos do trabalhador no que diz respeito à exposição a ruído intenso.

Com relação à disfonia, os dados coletados a partir do estudo de caso fornecem base para colocar em discussão a questão da constatação de transtornos vocais em trabalhadores que elevam a intensidade de voz buscando superar os níveis de ruído e atingir o objetivo de comunicação. Apesar das informações obtidas não exemplificarem uma relação direta entre a ocorrência de casos de disfonia e ambientes ruidosos, as condições identificadas já caracterizam fatores influentes para uma possível disfonia futura. Neste sentido, uma pesquisa mais ampla e um acompanhamento constante poderão ser mais eficazes no sentido de comprovar a relação entre os distúrbios vocais e a competição com o ruído de fundo em ambientes industriais.

A partir do trabalho realizado foi possível concluir que a PAIR e a disfonia são doenças a serem consideradas dentro do estudo da ergonomia e da segurança ocupacional. Os engenheiros de produção, como parte da equipe que investiga as condições de trabalho, devem participar e contribuir efetivamente para as pesquisas acerca da saúde do trabalhador. A busca por qualidade de vida no setor operacional da empresa garante uma maior produtividade e cumpre o dever ético de proteger a integridade física e psicológica do ser humano.

\section{Referências Bibliográficas}

AJAX SEGURANÇA E MEDICINA DO TRABALHO LTDA. Histogramas referentes à medição de ruído para diferentes funcionários durante a jornada de trabalho de 1 dia. Maio de 2001. Rua Tupis, 38 / s1904 - Centro - Belo Horizonte - MG. Tel: (31) 32241107.

BEHLAU, Mara, PONTES, Paulo. Avaliação e tratamento das disfonias. São Paulo: Lovise, 1995.

BEHLAU, Mara, RODRIGUES, Sandra, AZEVEDO, Renata, GONÇALVES, Maria Inês, PONTES, Paulo. Avaliação e terapia de voz. In: LOPES FILHO, Otacílio. Tratado de fonoaudiologia. São Paulo: Roca, 1997.

BESS, Fred H., HUMES, Larry E. Fundamentos de audiologia. Trad. Marcos A. G. Domingues. 2. ed. Porto Alegre: ArtMed, 1998.

BRASIL. Legislação Brasileira. Disponível na Internet via www.brasil.gov.br. Documentos visualizados em 15 de abril de 2002.

GRANDJEAN, Etienne. Ruído. In: GRANDJEAN, Etienne. Manual de ergonomia: adaptando o trabalho ao homem. 4. ed. Trad. João Pedro Stein. Porto Alegre: Artes Médicas, 1998.

KATZ, J. Tratado de audiologia clínica. 3. ed. São Paulo: Manole, 1989. 
LOPES FILHO, Otacílio, CAMPOS, Carlos Alberto H. de. Tratado de Otorrinolaringologia. São Paulo: Rocca, 1994.

MARCHESAN, I. Q., ZORZI, J. L. \& GOMES, I.C.D. Perda auditiva induzida pelo ruído: estudo de um instrumento de auto-avaliação para trabalhadores. In: MARCHESAN, I. Q., ZORZI, J. L. \& GOMES, I.C.D. Tópicos em fonoaudiologia. vol IV. São Paulo: Lovise, 1997/1998.

MCR DO BRASIL LTDA. Relatório de Bens. 2002. Av Francisco Firmo de Matos, 1269. Riacho das Pedras - Contagem - MG. Telefax: (31) 3391-3633. comercial@mcrdobrasil.com.br

MORAES, Ana Maria de, MONT'ALVÃO, Cláudia. Ergonomia: conceitos e aplicações. 2. ed. Rio de Janeiro: 2AB, 2000.

OSHA. U.S. Department of Labor - http://www.osha.gov/. Considerações a respeito do PCA (Programa de Conservaçẫo Auditiva). Disponível na Internet via http://www.osha.gov/Publications/osha3074.html Documento visualizado em 15 de abril de 2002.

PEDROTTI, Irineu Antonio. Doenças profissionais ou do trabalho. 2. ed. atual. ampl. São Paulo: Universitária de Direito, 1998.

RUSSO, Iêda C. Pacheco. Acústica e psicoacústica aplicadas à fonoaudiologia. 2. ed. rev. ampl. São Paulo : Lovise, 1999.

RUSSO, Iêda C. Pacheco, SANTOS, Teresa M. Momensohn dos. A prática da audiologia clínica. 4. ed. rev. aum. São Paulo: Cortez, 1993. p. 246-248.

SANTOS, Neri dos, et. al. Antropotecnologia: a ergonomia dos sistemas de produção. Curitiba: Gêneses, 1997. 